\title{
Prostituição, neoconservadorismo e pandemia - o Movimento de Prostitutas e os desafios da Covid-19
}

Prostitution, neoconservatism, and pandemic movement of sex workers and the challenges of COVID-19 Marlene Teixeira Rodrigues*

\begin{abstract}
Resumo - Este texto analisa o acesso à direitos de pessoas que exercem a prostituição, no contexto da pandemia e tendo em conta, o avanço da extrema direita e do neoconservadorismo no Brasil e suas repercussões na esfera da ação estatal. $O$ avanço conservador - que se delineou antes da eleição de Bolsonaro e da pandemia, ganhou contornos dramáticos com a chegada da Covid-19. A análise das iniciativas realizadas por organizações do Movimento de Prostitutas, no período da pandemia, identificadas mediante pesquisa documental, revela os desafios, a agenda e as estratégias adotadas pelo Movimento, diante do desmonte e desfinanciamento das ações governamentais, patrocinado pelo novo governo. A se destacar a construção de articulações com diferentes sujeitos políticos, de diferentes esferas, a fim de fazer frente às demandas (novas e velhas) agudizadas pela pandemia e à ausência de apoio do governo federal.
\end{abstract}

Palavras-chave: prostituição; neoconservadorismo; trabalho sexual; Covid-19

\begin{abstract}
This paper analyzes the advance of the extreme right and neoconservatism in Brazil and its repercussions in the sphere of state action and in the field of rights related to the exercise of prostitution, in the context of the pandemic. The conservative advance was outlined before the election of Bolsonaro and the pandemic, gained dramatic contours with the arrival of the COVID-19 pandemic. The analysis of initiatives carried out by organizations of the movement of sex workers in the period of the pandemic, identified through documentary research, reveals the challenges, agenda and strategies adopted in the face of the pandemic and the dismantling and defunding of government actions, sponsored by the new administration. This paper also highlights the construction of articulations with different political subjects, from different spheres, in order to face demands (new and old) sharpened by the pandemic and the lack of support from the federal government.
\end{abstract}

Keywords: prostitution; neoconservatism; sex work; COVID-19.

\footnotetext{
* Assistente Social. Pós-doutora em Sociologia (UAB-2015) e em Democratização e Direitos Humanos (UNSAM2011). Docente do Programa de Pós-graduação em Política Social (UnB). Líder do Genposs - Grupo de Estudos e Pesquisas em Gênero, Política Social e Serviços Sociais (CNPq). Pesquisadora do NEPeM - Núcleo de Estudos e Pesquisas sobre a Mulher (UnB); da REFAPS - Rede de Estudos e Pesquisa sobre Família e Política Social (UFSC). Email: marte@unb.br. ORCID: https://orcid.org/0000-0001-9418-7192.
} 


\section{Apontamentos introdutórios}

São apresentadas neste texto algumas reflexões acerca das questões trazidas pela Covid-19 referentes à prostituição, às pessoas que sobrevivem dessa ocupação e às organizações de defesa de direitos de prostitutas. Em um contexto marcado pela ascensão neoconservadora ${ }^{1}$, analisamos os temas e as ações encampados pelas entidades que integram o Movimento Brasileiro de Prostituta ${ }^{2}$ para o enfrentamento da pandemia e a garantia de direitos. Para efeitos de organização da apresentação, após estes apontamentos iniciais, são discutidas as principais vertentes presentes no debate teórico atual sobre prostituição e que servem de referencial no exame das referidas iniciativas. Em continuação, se examina a atuação de setores neoconservadores ligados ao fundamentalismo religioso e ao feminismo abolicionista direcionada ao combate à prostituição. Finalmente, voltamos a atenção para as estratégias e iniciativas adotadas pelo movimento ante os desafios colocados no contexto da pandemia.

De início vale assinalar que a prostituição se insere dentro da diversidade de trabalhos sexuais que integram a indústria do sexo. ${ }^{3}$ A prostituição é entendida, pois, como uma das modalidades de trabalho sexual, compondo a complexa e diversificada indústria do sexo, e engloba diferentes formas de organização. Refere-se ao "campo amplo do complexo afetivosexual em que múltiplas formas de troca são registradas para atender às necessidades humanas de afeto, cuidado pessoais e relações sexuais" - nas palavras de Laura Agustín (2002, p. 534 - tradução nossa) -, e envolve valores monetários ou outros valores. ${ }^{4}$ É importante atentar para a existência de diferentes modalidades de prostituição e suas dinâmicas específicas, dentro da indústria sexual; conforme assinalado por Cristina Garaizabal (2006, p. 66 - tradução nossa):

Há diferentes maneiras de exercê-la e vivê-la. Classe social, nível cultural, idade, aparência física, nacionalidade, etnia, gênero (porque nem todas as pessoas que exercem prostituição são mulheres; há homens assim como mulheres transgêneros), e muitos outros fatores influenciam como a prostituição é exercida e até mesmo como a sociedade considera a prostituição.

\footnotetext{
${ }^{1} \mathrm{O}$ texto recupera algumas reflexões apresentadas em conferências realizadas pela autora durante congressos e reuniões do grupo de estudos durante os anos de 2018 e 2019.

${ }^{2}$ Contando com mais de 20 associações estaduais, o Movimento Brasileiro se organiza hoje em três entidades de âmbito nacional: a Rede Brasileira de Prostitutas (1987), a Central Única de Trabalhadoras e Trabalhadores Sexuais (CUTS) (2015) e a Articulação Nacional de Profissionais do Sexo (Anps/Anprosex) (2016).

${ }^{3}$ Segundo Agustín (2005), o uso do termo "prostituição" contribui para obscurecer a diversidade de modalidades de trabalhos sexuais existentes, assim como o mercado sexual, e a abordagem sobre os sujeitos que vendem sexo tende a aumentar a estigmatização.

${ }^{4}$ Vale destacar que, embora a possibilidade de realização do ato sexual seja elemento central na relação estabelecida, nem sempre ele se realiza.
} 


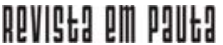

\} PROSTITUIÇÃO, NEOCONSERVADORISMO - RODRIGUES, M. T. \}

DOI: $10.12957 /$ REP.2021.60304

Embora o estigma em relação à prostituição não tenha cessado, no último quarto do século XX "a criação de "espaços práticos e intelectuais para as vozes das mulheres prostitutas", decorrente do surgimento dos referidos movimentos, constitui elemento distintivo desse período" (SCAMBLER; SCAMBLER, 1997 apud TEIXEIRA, 2003, p. 110). Esse novo cenário, entretanto, não foi capaz de obstaculizar a utilização, ainda hoje, do termo prostituição em nossa sociedade para referir-se a condutas sexuais diversas da acima mencionada como atos de prostituição. Isso revela o conteúdo moral e o estigma que ainda cercam a atividade e a importância dos modos de percepção na definição social dela (AGUSTín, 2002; 2008a; 2008b; JULIANO, 2002; 2006). Mais recentemente, o revigoramento do discurso conservador e de valores tradicionais tem confrontado o culto ao hiperindividualismo hedonista. É neste cenário que se assiste ao recrudescimento das tensões e ao surgimento de novas inflexões que impactam diretamente o campo da prostituição. Simultaneamente, observa-se a discriminação e a exclusão dos sujeitos e das práticas concretas, desencadeadas em diferentes cidades e países, concomitante à expansão e à diversificação da indústria do sexo, bem como à naturalização da prostituição e de práticas "virtuais" (AGUIAR, 2017; AGUSTÍN, 2008b; JULIANO, 2006; 2012; TEIXEIRA, 2017).

Este é o cenário em que se dá a reação neoconservadora e em que se observa o início das "guerras sexuais" no Brasil, impactando diretamente trabalhadoras/es sexuais e suas organizações. Antes de examinar o quadro delineado a partir da chegada da pandemia, já sob o governo Bolsonaro, tratemos de analisar mais detidamente os termos em que está construído o debate teórico.

\section{Entre a exploração e a autodeterminação - trabalho sexual em tempo de pânicos sexuais}

Veremos nesta seção as principais tendências no debate contemporâneo em torno da prostituição/trabalho sexual identificadas na revisão bibliográfica realizada. Inicialmente vale assinalar a persistência de perspectivas antagônicas sobre a temática, inclusive dentro do próprio feminismo. Além disso, destaca-se a contestação da perspectiva da autodeterminação ${ }^{5}$ por abordagens alinhadas ao abolicionismo e ao regulamentarismo ${ }^{6}$, que reemergiram com ímpeto renovado no bojo da ascensão da chamada "nova direita" ${ }^{\prime \prime}$ e do neoconservadorismo. Essa tendência revela a emergência de

\footnotetext{
${ }^{5}$ Denominada "perspectiva do terceiro mundo" por Kempadoo (2005) e "modelo trabalhista" por Piscitelli (2012). ${ }^{6}$ Conforme Rago (1991, p. 266-267), o regulamentarismo propugna "o controle dos territórios desejantes pelo Estado", assim como os "lugares da existência das casas de tolerância e dos bordéis nas cidades, os horários de circulação das mulheres, a inspeção médica, entre outros aspectos"; o abolicionismo, crítico da proposta do Estado como "cafetão", defende a extinção não só de qualquer controle estatal, mas também da atividade.

${ }^{7}$ De acordo com Esther Solano (2018), a nova direita no Brasil se caracteriza por agregar princípios ultraliberais com os valores da extrema-direita.
} 
"um novo tipo de capitalismo global", cuja dinâmica, marcada pela extração e destruição, produz novos e velhos tipos de "expulsões", que atingem indistintamente nações "ricas" e pobres, ainda que estas últimas com intensidade muito superior (SASSEN, 2016).

Essa "nova forma de vida", engendrada pelo "capitalismo flexível" e pela ideologia neoliberal, tem como principais características conforme Marilena Chauí (1997, p. 32): a insegurança, o medo, a dispersão e "o sentimento do efêmero e da destruição da memória objetiva dos espaços". Essas condições, segundo a autora, impulsionam a aplicação no mercado futuro, a financeirização, a busca por "uma autoridade política forte, com perfil despótico" e o fortalecimento de "instituições, sobretudo a família, e o retorno ao das formas místicas e autoritárias ou fundamentalistas de religião", assim como a valorização de "suportes subjetivos da memória (diários, biografias, fotografias, objetos)", bem como a ascensão do conservadorismo.

"Nova direita", "onda neoconservadora" ou ainda "trumpização da política" - segundo Esther Solano (2018, p. 3), essas são algumas das terminologias que têm sido utilizadas para referir-se a processos de "reorganização de grupos conservadores e/ou da direita radicalizada que tem abrangência mundial e, como não poderia ser diferente, com fortes reflexos no Brasil". O neoconservadorismo, alçado ao topo no governo de W. Bush, é a base ideológica dessa "nova direita", de acordo com Kristol (Kristol apud FINGUERUT, 2008). Defende "um Estado mais forte, porém com menos impostos"; uma política externa de defesa do patriotismo e no rechaço a "um governo mundial", por entender que este resultaria em "tirania generalizada"; e na adoção de uma política interna pautada em "distinguir amigos de inimigos" (p. 20).

À medida que avança o século XXI, assiste-se ao fortalecimento, na Europa, nos EUA e na América Latina, desses discursos neoconservadores e de organizações na esfera da nova direita, que apelam fortemente à xenofobia, ao racismo, ao sexismo e a outras bandeiras "segregacionistas". As "guerras sexuais" merecem especial atenção nesta conjuntura. Essas "guerras", assim como aquelas levadas a cabo pela direita norte-americana dos Estados Unidos a partir da década de 1970, destaca Gayle Rubin (1989), têm como alicerce o "pânico sexual" e o "terror erótico". Representam "alterações de longo alcance na regulação do comportamento sexual e revogam importantes liberdades civis" (RUBIN, 1989, p. 123). É uma "contra-ofensiva sexual à direita", em reação aos avanços na liberalização sexual promovidos pelo movimento feminista, em que o pânico moral tem centralidade. (AGUSTÍN, 2008b; BUTLER, 2015; FINGUERUT, 2008; JULIANO, 2012; SASSEN, 2016; SOLANO, 2018). O pânico moral, assinala Rubin (1989, p. 159),

cristaliza medos e ansiedades generalizadas e muitas vezes os confronta, sem olhar para as causas reais dos problemas e características 
que mostram, mas movendo-os para os 'tipos diabólicos de um determinado grupo social (muitas vezes imoral 'Ou os degenerados')'. A sexualidade desempenhou um papel particularmente importante em tais pânicos e 'os desviantes sexuais foram bodes expiatórios onipresentes'.

Essas políticas sexuais, apoiadas por "feministas antipornografia", assim como "as políticas de inibição ao suposto 'tráfico sexual'", como enfatiza Rubin (apud MOSCKOVICH, 2012, p. 966), constituem "poderosos instrumentos legais para punir, perseguir e desmantelar tais comunidades". E, assim como ocorreu nas primeiras décadas do século XX - em que a desinformação sobre tráfico de escravas brancas e prostituição era usada para criar um "pânico moral sobre a sexualidade das mulheres" -, se vê contemporaneamente a utilização da taxonomia do "tráfico sexual"/"tráfico de mulheres" como principal inspiração de parte da legislação e dos movimentos sociais de caráter punitivista e cumprindo função similar.

Neste mesmo sentido, Solano, Ortellado e Moretto (2017, p. 2) chamam a atenção para a multiplicação das chamadas "guerras culturais", processos por meio dos quais "temas como o direito dos homossexuais, a legalização do aborto, o controle de armas e a legalização das drogas passam a ganhar proeminência no debate político". "Conservadores" e "progressistas" assumem posições antagônicas a partir de argumentos de caráter moral (MENDONÇA, 2019; SOLANO; 2018; SOLANO, ORTELLADO; MORETTO 2017). Como destacado por Andrea Dip (2018, p. 159),

No Brasil, essa reação tem características próprias. Uma delas vem da aproximação entre uma direita orgulhosa de si e a Igreja Evangélica, unidas pelo medo de um inimigo que vem para 'destruir a família tradicional', os 'valores cristãos', o status quo e que, por vezes, sem lastro com a realidade, toma rosto no comunismo, no feminismo, no movimento negro, na comunidade LGBTQ e em qualquer participação social que peça por igualdade de direitos e por uma discussão mais profunda sobre seus papéis na sociedade.

É neste quadro mais geral de ascensão do neoconservadorismo, concomitante à expansão e à diversificação da indústria do sexo, que ganham impulso discursos e propostas abolicionistas referentes à prostituição. Em diferentes países e continentes, cresce o confronto entre o discurso abolicionista e punitivista e a perspectiva da autodeterminação em relação à prostituição. No debate da prostituição, observa-se, ademais, um novo cenário, em que conservadores de direita e feministas radicais têm adotado posições convergentes, forjando "uma estranha aliança", como assinala Juliano (2005).

Na noção partilhada por abolicionistas, a prostituição se constitui como uma violência sexista e, portanto, é uma exploração sexual. Nesse contexto, a prostituição não pode nunca ser definida como trabalho, pois 


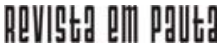

\} PROSTITUIÇÃO, NEOCONSERVADORISMO - RODRIGUES, M. T. \}

DOI: $10.12957 / R E P .2021 .60304$

é um exercício abusivo de poder, em que a mulher não tem poder algum sobre seus clientes ou possibilidade de escolha. Justifica-se a impossibilidade de se considerar a prostituição como trabalho a partir de dois argumentos: conforme o primeiro, a noção de consentimento simplesmente não existe na prostituição, portanto, pode apenas ser igualada à escravidão. O segundo remete à sexualidade da prostituta e à violência implícita na necessidade de se desconectar de seu lado sexual, uma parte primordial do ser, para exercer a atividade.

Quando se fala em prostituição, diferentes noções de exploração são acionadas. O Relatório global da Organização Internacional do Trabalho (OIT), de 2005, trouxe outra noção de exploração. Isso significou uma importante inflexão à medida que procura distinguir a prostituição forçada em casos de exploração sexual comercial de pessoas adultas - da prostituição voluntária, na qual não estaria presente a exploração (PISCITELLI, 2012).

Entretanto, há também o segmento de feministas que se alinham com a abordagem dos movimentos das prostitutas, entendendo a prostituição como trabalho. Autoras referenciais nesse debate, como Laura Agustín, Dolores Juliano e Kamala Kempadoo, abordam a prostituição como trabalho sexual, a partir da dinâmica capitalista global, em que se inscreve a indústria do sexo e as migrações. Laura Agustín (2008a) observa que os discursos que conseguiram se hegemonizar em esferas transacionais, em torno do tema do "tráfico de pessoas para fins de exploração sexual", confluem com a perspectiva abolicionista, passando a mobilizar organizações e entidades em todo o mundo a partir da primeira década do século XXI.

A respeito desses discursos, Agustín (2005) enfatiza que, mesmo aqueles que não falam sobre "tráfico", frequentemente usam abstrações teóricas como "violência de gênero" ou "exploração", que são conceitos de avaliação - para situações inerentemente muito complexas (AGUSTIN, 2005, p. 123). Além disso, servem de justificativa à constituição do que a autora denomina de "indústria do resgate", iniciativas salvacionistas que, desconsiderando a complexidade das questões inscritas nas trajetórias de migração e a voz dos sujeitos "resgatados" e encapsulados no lugar de "vítimas", acabam por marginalizar ainda mais aqueles/as a quem se propõem proteger - mulheres migrantes, indocumentadas -, especialmente quando envolvendo trabalho na indústria do sexo (AGUSTíN, 2008a; 2008b; GARAIZABAL, 2006; KEMPADOO, 2005; JULIANO, 2006; 2012; 2014; PISCITELLI, 2008).

Esse discurso "moralizador e vitimista" impregna a maioria dos "documentos oficiais, as representações midiáticas, as investigações reconhecidas e subvencionadas e as práticas de política social sobre os 'problemas' da 'prostituição e seus vínculos com a migração aos países do Primeiro Mundo'" (GARCíA, 2004, p. 13 - tradução nossa). O denominado 


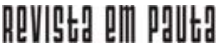

\} PROSTITUIÇÃO, NEOCONSERVADORISMO - RODRIGUES, M. T. \}

DOI: $10.12957 /$ REP.2021.60304

"Protocolo de Palermo" ${ }^{8}$, em particular, ilustra esta situação e tem representado, do ponto de vista político, uma diretriz fundamental e um poderoso elemento de justificativa para estudos e políticas sobre exploração sexual e prostituição a partir dos anos 2000, também adotada no Brasil (SPRANDEL, 2007; TEIXEIRA, 2017).

A sinonimização entre prostituição e exploração sexual, vitimização e infantilização de mulheres é marca do referido protocolo e se espraia pela legislação e pelas políticas públicas no Brasil. Como destaca Castilho (2008) em seu estudo, "sob um discurso tutelar está presente o não reconhecimento da capacidade da mulher de exercer o direito sobre o próprio corpo, bem como a estigmatização social da prostituta como forma de estabelecer o papel e o lugar da mulher na sociedade" (CASTILHO, 2008, p. 113). Dolores Juliano chama atenção, ainda, para um efeito cruel dessas intervenções: o silenciamento da voz dos sujeitos - transformados em vítimas - e sua substituição por seus salvadores. Enfim, dentre as inúmeras repercussões negativas desses tipos de abordagens, os efeitos mais graves estão relacionados ao impacto sobre as "vítimas", já que a maior estigmatização tende a recair sobre elas.

Vejamos como se dá a atuação neoconservadora no país em relação à prostituição, antes e depois da chegada da pandemia. Nesse sentido, destaca-se o quadro delineado e as repercussões na vida de trabalhadores sexuais, a partir da explosão dos casos de Covid-19 em todo o país no primeiro semestre de 2020 sob o governo de Jair Bolsonaro (AGUIAR, 2017; FERRAZ; TEIXEIRA, 2019; SILVA; TEIXEIRA, 2019; TEIXEIRA, 2003; 2017).

\section{Neoconservadorismo e prostituição em tempos pandêmicos - miradas sobre uma guerra tupiniquim}

Inicialmente, vale assinalar que o Movimento Brasileiro de Prostitutas, ao longo de mais de três décadas de existência, tem revelado como uma de suas principais características a capacidade de articular-se e construir alianças com diferentes sujeitos no campo da sociedade civil e do Estado. Essa característica ganha ainda mais relevância frente ao cenário delineado a partir da chegada de Bolsonaro à presidência (ABIA, 2013; BARRETO, 2016; CORRÊA et al., 2011; LEITE, 2009; PRADA, 2018; REZENDE, 2016; TEIXEIRA, 2009; 2017).

Antes da eleição presidencial de 2018, a ascensão do neoconservadorismo ganhou visibilidade no país com o crescimento das igrejas evangélicas, especialmente mediante sua atuação na mídia e na política. $\mathrm{O}$ império midiático construído pela Igreja Universal do Reino de Deus (IURD)

\footnotetext{
${ }^{8}$ Protocolo de Prevenção, Supressão e Punição do Tráfico de Pessoas, Especialmente Mulheres e Crianças, firmado em 2004, em complementação à Convenção das Nações Unidas Contra o Crime Organizado Transnacional (Untoc), de 2003, comumente conhecida como Convenção de Palermo.
} 


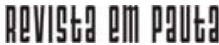

\} PROSTITUIÇÃO, NEOCONSERVADORISMO - RODRIGUES, M. T. \}

DOI: $10.12957 / R E P .2021 .60304$

e seu coordenador, o bispo Edir Macedo, com a aquisição da Rede Record de Televisão, assim como a conformação de uma bancada parlamentar, coesa e atuante no Congresso Nacional e em estados e municípios de todo o Brasil, expressa esse movimento.

Como a pesquisa realizada por Andréa Dip (2018) mostra, além de garantir a "manutenção de seus privilégios - isenção tributária e concessões de TVs e rádios", o principal interesse da bancada evangélica é fazer avançar um conjunto de "pautas conservadoras, como a proibição do aborto, mesmo para os casos legalmente previstos, a proibição da discussão sobre gênero e prevenção da homofobia nas escolas, o retrocesso de direitos de grupos vulneráveis, como os travestis e transexuais" (AMARAL, 2018, I. 118).

Relator do Projeto de Lei $\mathrm{n}^{\circ} 377 / 2011$, que propõe criminalizar a contratação de serviços sexuais e ex-presidente da FPE, o deputado federal João Campos, do Partido Republicano (PRB) ${ }^{9}$, em seu discurso, ilustra bem a concepção que sustenta o projeto conservador (AGUIAR, 2017; DIP, 2018; TEIXEIRA, 2017). Como o deputado assinalou para Andréa Dip (2018, p. 521) durante entrevista:

'A Frente Parlamentar Evangélica tem exercido um papel muito importante em contribuir com o processo legislativo, porque priorizou algumas bandeiras que são relevantes para a sociedade brasileira, como, por exemplo, a defesa da família tradicional' [...]. 'Outra bandeira que defendemos é a defesa da vida desde a concepção, os direitos do nascituro, a proibição do aborto, do infanticídio; os direitos da mulher também, mas, em especial, os direitos do ente humano que está sendo gerado'.

Expressão maior de sua estratégia política, conhecida pela alcunha de "bancada da Bíblia", o braço parlamentar desses neoconservadores ligados a igrejas fundamentalistas articulou suas principais ofensivas antes de alcançarem a presidência. Com a chegada de Bolsonaro à presidência da República, o neoconservadorismo tupiniquim avançou para o Executivo, gerando fortes repercussões na vida daqueles e daqueles que sobrevivem do trabalho sexual e, também, na dinâmica das organizações de defesa dos direitos de prostitutas.

Duas iniciativas do governo Bolsonaro merecem destaque nesse sentido, pelo modo como influenciam ações que se relacionam à prostituição e às pessoas que a exercem: a nomeação de Damares Alves para o Ministério da Família, da Mulher e dos Direitos Humanos; e a extinção do antigo Departamento Nacional de IST/HIV/Aids ${ }^{10}$. Assessora parlamentar da "bancada da Bíblia" por quase 20 anos no Congresso Nacional, a ministra Damares

\footnotetext{
${ }_{9}^{9}$ O PRB, conhecido por Republicano, fundando em 2005, é ligado á IURD e presidido por um bispo da Igreja.

${ }^{10} \mathrm{O}$ antigo e poderoso Departamento de HIV/Aids foi anexado, juntamente com o setor de hepatites virais, ao novo Departamento de Doenças de Condições Crônicas e Infecções Sexualmente Transmissíveis.
} 


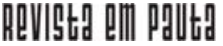

\} PROSTITUIÇÃO, NEOCONSERVADORISMO - RODRIGUES, M. T. \}

DOI: $10.12957 /$ REP.2021.60304

esteve à frente de grande parte da movimentação da referida bancada no Parlamento e constitui uma das principais porta-vozes e guia do grupo mais ligado ao neopentecostalismo. No governo federal, esse grupo se destaca, em diferentes oportunidades, ao chamar a atenção para o projeto "religioso", representado pela eleição de Bolsonaro, e por fazer o papel de "filtro" no descarte de projetos que considera atentatórios às concepções que defende. ${ }^{11}$

Quanto às mudanças no Ministério da Saúde, para além de reorganização burocrática, o que se tem observado é a substituição das equipes técnicas existentes, o desfinanciamento das ações e o desmonte de projetos, impactando diretamente as ações desenvolvidas com financiamento ministerial. Dessa maneira, é nesse cenário que trabalhadoras sexuais e suas organizações se viram desafiadas a fazer frente às questões postas pela chegada da pandemia.

O primeiro aspecto que se destacou quanto aos desafios trazidos pela doença diz respeito às peculiaridades próprias ao exercício da prostituição e aos obstáculos que se apresentaram com a Covid-19. Isto porque, não obstante a diversidade de modalidades em que o trabalho sexual se organiza, grande parte do contingente de trabalhadoras sexuais se dedica à prostituição "à moda antiga". Ou seja, o corpo a corpo, que precede e viabiliza o encontro sexual, constitui parte central do trabalho. O sexo virtual, embora pareça à primeira vista a saída óbvia e mais fácil, não representa uma solução de fato. Além da necessidade de um bom celular com boa câmara e um pacote de dados robusto, essa modalidade de sexo envolve uma expertise tecnológica e remete a uma estética dificilmente acessível ao conjunto de trabalhadoras sexuais que se dedicam à prostituição. Assim, embora o tema tenha surgido nos debates travados online, não se podem aventar saídas exequíveis para a questão.

Esse foi o primeiro e mais importante desafio colocado pela necessidade de distanciamento social imposto pelo coronavírus. Assim como outros trabalhadores precarizados, prostitutas se viram pressionadas a continuar trabalhando pela falta de recursos financeiros e dificuldades de acesso ao Auxílio Emergencial, criado pelo Congresso Nacional a fim de amparar esses segmentos.

A partir do mês de maio de 2020, com o avançar da pandemia e as restrições de locomoção e de funcionamento de estabelecimentos comerciais adotadas por prefeituras e estados, foram reduzidas as possibilidades de trabalhadoras sexuais se manterem em atividade. Desse modo, aumentaram as demandas junto às organizações do movimento. Com recursos financeiros restringidos, sem contar com apoio do MS em função do novo cenário federal, as entidades têm exercitado o que aprenderam a fazer de melhor: articular-se com outros sujeitos políticos tendo em vista atender às

${ }^{11}$ Além do PL 377/2011 se destacam o PL 718014 e o PL 4931/2016 que tratam direitos sexuais. (DIP, 2018). 


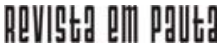

\} PROSTITUIÇÃO, NEOCONSERVADORISMO - RODRIGUES, M. T. \}

DOI: $10.12957 / R E P .2021 .60304$

demandas recebidas, como foi possível observar no levantamento documental realizado ${ }^{12}$ e em conversas informais com algumas integrantes do movimento.

Assim, ante à necessidade de obtenção de alimentos e produtos de higiene e limpeza, essas entidades se articularam com secretarias municipais e estaduais de saúde, de assistência social, de direitos humanos e de diversidade, assim como com organizações não governamentais diversas, com maior estrutura e recursos para oferecer o apoio necessário. Associações de soropositivos, de LGBTQIA e associações culturais se destacaram entre estes parceiros. A realização de vaquinhas e sorteios virtuais também foi estratégia acionada em busca de recursos financeiros para aquisição de tais produtos.

As organizações que integram o movimento têm se utilizado também dessas articulações para dar visibilidade às questões relacionadas ao cotidiano do trabalho sexual e às suas agendas. Com esse objetivo, têm realizado ou participado de lives sobre diferentes temas e com diferentes interlocutores. Entre abril e novembro, identificamos 16 eventos com a participação de integrantes das seguintes entidades ligadas ao movimento de prostitutas: Anprosex, Cuts, Rede Brasileira de Prostitutas, Aprosma, Aprosmig, Aprospe, Aprospi, Coletivo Coisa de Puta, Coletivo Rebu, Grupo de Prostitutas da Área Central (Gempac), Casa NEM, Trans-revolução, Núcleo de Estudos sobre Prostituição (NEP) e Tulipas do Cerrado.

Esses eventos foram promovidos pelas próprias entidades ou em articulação com organizações parceiras, tais como o Movimento Nacional de Cidadãs Posithivas, Comunicação em Sexualidade (Ecos), Fundo Positivo, Faculdade de Medicina da UFMA, Faculdade de Saúde Pública da USP, Observatório da Prostituição, da UFRJ, e Faculdade de Saúde Pública, da UFF. Vale dizer que, no período que antecedeu as eleições municipais, ocorridas entre outubro e novembro, essas parcerias se estenderam também a candidaturas à vereança - duas candidaturas à vereança, em Pernambuco e no Rio Grande do Sul - interessadas em discutir as pautas específicas do movimento.

Em relação às pautas tratadas nessas ocasiões, uma olhada nos títulos informa: Trabalhadoras sexuais e mulheres vivendo com HIV/Aids conversam sobre a pandemia e o mundo digital; Saúde mental de trabaIhadoras sexuais e mulheres vivendo e convivendo com HIV/Aids; No trabaIho sexual me identifico como May - Prostitutas não vendem seus corpos elas vendem Fantasias! - Quer sabe mais...; ou ainda Igualdade de gênero e étnico-racial, os direitos sexuais e reprodutivos, a autonomia e a justiça social. Assim como os títulos, as conversas travadas pelas participantes durante esses eventos sinalizam para a existência de velhas e novas questões, que remetem ao (não) reconhecimento da prostituição como trabalho e dos direitos daquelas que a exercem. Sobretudo, os depoimentos com-

\footnotetext{
${ }_{12}$ Foram consultadas postagens de redes sociais, entre abril e novembro de 2020, como Facebook, Instagram e WhatsApp de entidades (Aprosba, Aprospi, Asprorn, Coletivo Rebu, Cuts, Daspu, entre outras), e sujeitos individuais e canais de YouTube.
} 


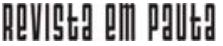

\} PROSTITUIÇÃO, NEOCONSERVADORISMO - RODRIGUES, M. T. \}

DOI: $10.12957 /$ REP.2021.60304

partilhados nessas ocasiões reafirmam as dificuldades de enfrentamento da pandemia, decorrentes de um velho conhecido: o estigma de puta, agravado no cenário atual pela falta de recursos públicos. Esse estigma, como destacado por Juliano (2000, p. 17), é um aspecto "tão determinante que resulta muito difícil para a maioria das pessoas avaliar os problemas relacionados com a prostituição como o fariam com qualquer outro trabalho".

\section{Apontamentos finais}

Diante do exposto, o que dizer então sobre os desafios colocados pela Covid-19? As prostitutas, que mal se afastaram, voltaram ao trabalho sexual diante da impossibilidade de vislumbrar uma alternativa de sobrevivência. O quadro econômico mais geral no país registra queda recorde do PIB e a marca de mais de 14 milhões de desempregados; quantitativo que já significa mais de $50 \%$ da população economicamente ativa fora do mercado de trabalho, com maior impacto sobre as pessoas que ganham menos e são menos escolarizadas.

As perspectivas na esfera das políticas sociais, sob o receituário da nova direita, apontam para o aprofundamento de iniciativas orientadas pela lógica das "expulsões" e da necropolítica. Mulheres e população negra, segregadas nas periferias, continuarão a ocupar as piores posições e a viver nas condições mais precárias. O desmonte do Sistema Único de Saúde é mais um agravante. $\mathrm{O}$ horizonte para os segmentos mais pobres, que sobrevivem do trabalho sexual, não é muito diferente. Se é fato que há demandas e necessidades específicas relacionadas ao mundo do trabalho, há muitas outras, idênticas a tantos outros sujeitos de igual idade, geração, raça/etnia, gênero e região. Sublinhamos como alento a resiliência e a capacidade revelada pelas entidades e pelo movimento em construir alternativas cotidianamente.

A emergência dessa direita fundamentalista, consagrada com a eleição de Bolsonaro, não deve, porém, provocar estranhamento. Suas razões repousam no autoritarismo secular brasileiro - uma de nossas principais características em termos de cultura política -, na rejeição às mudanças promovidas pelas políticas de ação afirmativa, particularmente no que se refere ao ensino superior e às universidades federais, e em outras diferentes medidas de ação afirmativa para população negra e pobre, como a Lei do Trabalho Doméstico, que estendeu a esse segmento os direitos trabalhistas desfrutados até então pelas demais categorias de trabalhadores.

Assim como a democracia, a cidadania no Brasil jamais foi alcançada igualmente para todas as classes. Como bem o sabem as trabalhadoras e trabalhadores sexuais, os marcadores de raça, gênero, classe, território e orientação sexual são os principais determinantes da abrangência de nossa cidadania, que ao longo desses mais de 30 anos permaneceu uma "cidadania regulada". Confrontar esses marcadores é também sobre viver. 


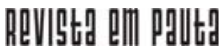

\} PROSTITUIÇÃO, NEOCONSERVADORISMO - RODRIGUES, M. T. \}

DOI: $10.12957 /$ REP.2021.60304

\section{Referências}

ABIA. Análise do contexto da prostituição em relação a direitos humanos, trabalho, cultura e saúde no Brasil. Rio de Janeiro: ABIA, 2013.

AGUIAR, B. M. A influência do conservadorismo no debate sobre prostituição no parlamento brasileiro - Os projetos de lei n. 377/2011 e n. 4211/ 2012. Trabalho de Conclusão de Curso (Bacharelado em Serviço Social) Universidade de Brasília, Brasília, 2017. Mimeo.

AGUSTÍN, L. M. Mujeres migrantes ocupadas en servicios sexuales. Mujer, Imigración y Trabajo, Madrid, 2002.

AGUSTÍN, L. M. La industria del sexo, los migrantes y la familia europea. Cadernos Pagu, Campinas, n. 25, jul.-dez. 2005a.

AGUSTÍN, L. M. New research directions: the cultural study of commercial sex, sexualities. 2005b. Disponível em: sex.sagepub.com. Acesso em: 20 dez. 2011.

AGUSTÍN, L. M. Sex at the margins. Migration, labor, markets and the rescue industry. New York: Zed Books Ltd., 2008a.

AGUSTÍN, L. M. Trabajo sexual y derecho al trabajo. 2008b. Disponível em: https://www.lauraagustin.com/trabajo-sexual-y-derecho-al-trabajo-sexwork-and-the-right-to-work. Acesso em: 13 mar. 2014.

AMARAL, M. Prefácio - Uma Grande reportagem. In, DIP, A. Em nome de quem? A bancada evangélica e seu projeto de poder. Rio de Janeiro: Civilização Brasileira, 2018, I. 118.

BARRETO, L. S. A. Prostituição, a história recontada: transas sociais e institucionais em Belém. Monografia (Aperfeiçoamento/Especialização em Educação em Direitos Humanos e Diversidade) -Universidade Federal do Pará, Pará, 2016.

BUTLER, J. Quadros de guerra: quando a vida é passível de luto? Rio de Janeiro: Civilização Brasileira, 2015.

CASTILHO, E. W. V. de. A criminalização do tráfico de mulheres: proteção das mulheres ou reforço da violência de gênero? Cadernos Pagu, Campinas, n. 31, jul.-dez. 2008.

CHAUÍ, M. Ideologia neoliberal e universidade. In: OLIVEIRA, F. de; PAOLI, M. C. (Org.). Os sentidos da democracia. Petrópolis: Vozes, 1999.

CORRÊA, S. et al. Sexualidade e desenvolvimento: a política brasileira de resposta ao HIV/Aids entre profissionais do sexo. Rio de Janeiro: Abia, 2011.

DIP, A. Em nome de quem? A bancada evangélica e seu projeto de poder. Rio de Janeiro: Civilização Brasileira, 2018.

FERRAZ, M. L.; TEIXEIRA, M. L. O debate legislativo brasileiro sobre prostituição - A perspectiva dos sujeitos políticos [relatório de pesquisa]. Brasília: UnB, 2019. Mimeo. 


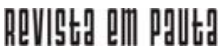

\} PROSTITUIÇÃO, NEOCONSERVADORISMO - RODRIGUES, M. T. \}

DOI: $10.12957 /$ REP.2021.60304

FINGUERUT, A. A influência do pensamento neoconservador na política externa de George W. Bush. Dissertação (Mestrado em Sociologia) - Programa de Pós-Graduação em Sociologia, Unesp, Araraquara, 2008. Mimeo.

GARAIZABAL, C. Por los derechos de las trabajadoras del sexo. Viento Sur, Madrid, n. 87, ano XV, jul. 2006.

GARCÍA, F. V. Prólogo. In: AGUSTíN, L. M. Trabajar em la industria del sexo, y otros tópicos migratorios. Barcelona: Gakoa, 2004.

JULIANO, D. La prostitución: el espejo oscuro. Barcelona: Icaria Editorial, 2002.

JULIANO, D. El trabajo sexual en la mira. Polémicas y estereotipos. Cadernos Pagu, Campinas, n. 25, dez. 2005.

JULIANO, D. Abolir la discriminación. Viento Sur, Madrid, n. 87, ano XV, jul. 2006.

JULIANO, D. Género y trayectorias migratorias en época de crisis. Papers Revista de Sociología, Barcelona, v. 97, n. 3, jul.-set. 2012.

JULIANO, D. Fe Feminismo y sectores marginales. Logros yretrocesos de un diálogo difícil, QAlter - CUADERNOS DE SOCIOANTROPOLOGIA, Barcelona, n. 8, 2014, p.1-11.

KEMPADOO, K. (Ed.). Trafficking and prostitution reconsidered: new perspectives on migration, sex work, and human rights. Colorado: Paradigm Publishers, 2005.

LEITE, G. S. Filha, mãe, avó e puta. A história de uma mulher que decidiu ser prostituta. Rio de Janeiro: Objetiva, 2009.

MENDONÇA, Filipe, ZAHRAN, Geraldo. A bolsonarização do Brasil, com Esther Solano. Chutando a Escada - podcast. Abril 2019. 26 de mar. de 2019. Disponível em: <https://podcasts.google.com/feed/aHR0cHM6Ly9jaHV0YW5kb 2Flc2NhZGEuY29tLmJyL2ZIZWQvcG9kY2FzdA?sa=X\&ved=0CAM Q4a UDahcK Ewiw9sSQuZ7wAhUAAAAAHQAAAAAQAQ>. Acesso em 08 de maio de 2020.

MOSCHKOVICH, M. B. F. G. Deviations: a Gayle Rubin reader. Revista Estudos Feministas, Florianópolis, v. 20, n. 3, set.-dez. 2012.

PISCITELLI, A. Entre as "máfias" e a "ajuda": a construção de conhecimento sobre tráfico de pessoas. Cadernos Pagu, Campinas, n. 31, jul.-dez. 2008. PISCITELLI, A. Exploração sexual, trabalho sexual: noções e limites. In: SEMINÁRIO CORPOS, SEXUALIDADES E FEMINILIDADES, Uerj, Rio de Janeiro, 2012.

PRADA, M. Putafeminista. São Paulo: Veneta, 2018.

REZENDE, P. G. Reinterpretando o corpo, gênero e sexualidade: uma perspectiva da ação coletiva do movimento brasileiro de prostitutas, enfoques online. Revista dos Alunos do PPGSA/IFCS/UFRJ, Rio de Janeiro, v. 15, dez. 2016. 
RUBIN, G. Reflexionando sobre el sexo: notas para una teoria radical de la sexualidad. In: VANCE, C. Placer y peligro: explorando la sexualidad femenina. Madrid: Revolución, 1989.

RAGO, M. Os prazeres da noite - Prostituição e códigos da sexualidade feminina em São Paulo (1890-1930). Rio de Janeiro: Paz e Terra, 1991.

SASSEN, S. Expulsões: brutalidade complexidade na economia global. Rio de Janeiro: Paz e Terra, 2016.

SASSEN, S. Contrageografías de la globalización. Género y ciudadanía en los circuitos transfonterizos. Madrid: Traficantes de Sueños, 2003.

SCAMBLER, A.; SCAMBLER, G. (Ed.). Rethinking prostitution - Purchasing sex in the 1990s. London: Routledge, 1997.

SILVA, A. G.; TEIXEIRA, M. As organizações de prostitutas e a luta pelo reconhecimento da cidadania e conquista de direitos [relatório de pesquisa]. Brasília: UnB, 2019. Mimeo.

SOLANO, E. Crise da democracia e extremismos de direita - Análise. São Paulo: Friedrich Ebert Stiftung Brasil, n. 42, mai. 2018. Disponível em: http:/ /library.fes.de/pdf-files/bueros/brasilien/14508.pdf. Acesso em: 8 ago. 2020.

SOLANO, E.; ORTELLADO, P.; MORETTO, M. "Guerras culturais" e "populismo anti- petista" nas ruas de 2017. São Paulo: Friedrich Ebert Stiftung Brasil, n. 10, jul. 2017. Disponível em: http://library.fes.de/pdf-files/bueros/ brasilien/13540.pdf. Acesso em: 8 ago. 2020.

SPRANDEL, M. A. A armadilha dos discursos: a criminalização das migrações na legislação brasileira e internacional. In: ENCONTRO ANUAL DA ANPOCS, 31, Caxambu, 2007. Disponível em: http://www.anpocs.com/ index.php/encontros/papers/31-encontro-anual-da-anpocs/st-7/st20-5/ 2982-marciasprandel-a-armadilha/file. Acesso em: 14 out. 2013.

TEIXEIRA, M. Polícia e prostituição feminina em Brasília: um estudo de caso. Tese (Doutorado em Sociologia) - Universidade de Brasília, Brasília, 2003. Mimeo.

TEIXEIRA, M. A prostituição no Brasil contemporâneo: um trabalho como outro qualquer? Katálysis, Florianópolis, n. 12, 2009.

TEIXEIRA, M. Prostituição, movimentos sociais e políticas públicas - Sobre que direitos se fala? Brasília: UnB, 2017. Mimeo.

DOI: $10.12957 /$ rep.2021.60304

Recebido em 01 de dezembro de 2020.

Aprovado para publicação em 15 de janeiro de 2021.

A Revista Em Pauta: Teoria Social e Realidade Contemporânea está licenciada com uma Licença Creative Commons Atribuição 4.0 Internacional. 